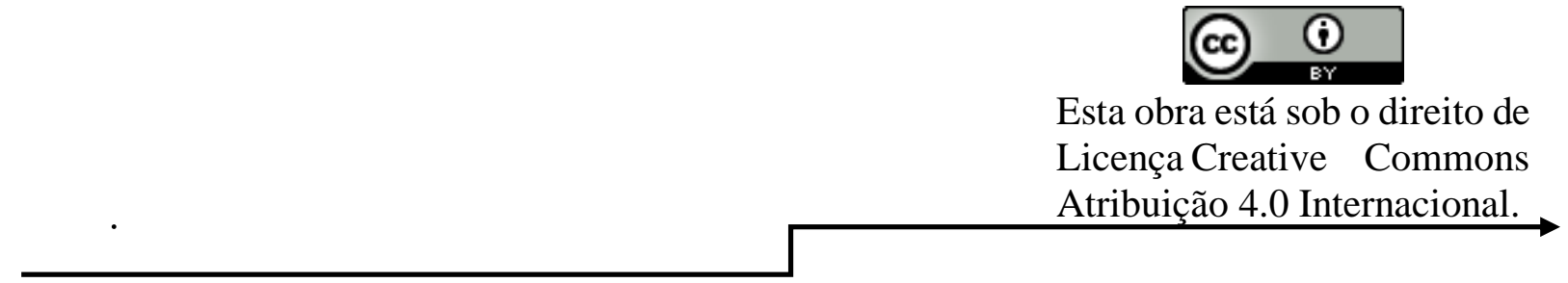

\title{
EVOLUÇÃO DO ENSINO DE LITERATURA NO BRASIL
}

\author{
Lucimairy Silva Lemos ${ }^{1}$ \\ Davi Silva Lemos ${ }^{2}$ \\ Eduardo Cabral da Silva ${ }^{3}$ \\ Ione Pereira da Silva ${ }^{4}$
}

\section{RESUMO}

A literatura brasileira, inicia-se no ano de 1836 e dura até os dias atuais. Ela inicia com o Romantismo e perpassa pelo Realismo, Naturalismo, Parnasianismo, Simbolismo, Prémodernismo, Modernismo e o Pós-modernismo. Ela recebe esse nome pois aconteceu após a Independência do Brasil, em 1822. O presente trabalho analisou produções de 2005 a 2020, nos sites BVS, Scielo e PubMed. O objetivo desta pesquisa foi analisar a importância da literatura ao longo dos tempos para a formação social e cultural do aluno. Trata-se de uma revisão sistemática integrativa. Os descritores estruturados no DeCs e MeSH. O período de coleta dos dados correu no mês de junho a dezembro de 2020. No qual adotou-se critérios de inclusão artigos científicos sobre o tema. Enquanto, os critérios de exclusão foram artigos científicos que não contemplaram a temática sobre literatura e a formação do caráter social. Espera-se que com novos estudos ocorra um novo olhar mediante a importância da literatura para a realidade atual.

PALAVRAS-CHAVE: Literatura. Social. Integrativa. Sistemática.

\footnotetext{
1 lucimairylemos@gmail.com

2 davisilvalemos81@gmail.com

3 edcs.cabral@gmail.com

4 ionepereira907@gmail.com
} 


\section{INTRODUÇÃO}

Os fatores que motivam a escolha do tema, partiu da constatação de análise da importância da literatura para a formação do caráter social e cultural do alunado ao longo da história. Desde os primórdios pode-se perceber que a mesma é uma das principais fontes que o ser social tem de se comunicar com os demais e até mesmo preservar premissas para as próximas gerações, assim como as lendas as mesmas tendem a abordar uma realidade vivida em um determinado momento e preservar diante de fatos e comportamentos detalhados em histórias, comportamentos diversos.

Neste estudo é realizada reflexões principalmente voltadas ao período do golpe militar, como professores, autores e demais pessoas passavam estudos mediante as obras e até mesmo escreviam sem ferir os parâmetros estabelecidos pelo governo ou até mesmo quando feriam o que realizavam.

SAVIANI (2009), apresenta concepções diversas nas quais é dito os preceitos ideológicos como uma proposta educativa em que media-se a pedagógica tecnicista direcionada ao objetivo ligado ao respeito a eficiência e também produtividade, fazendo ter um engajamento a ideais condizentes e a lógica do capital, em que estavam sempre atrelados a exploração e a subordinação de trabalhadores diversos diante o sistema opressor de economia que tem como um dos principais fatores beneficiar apenas os burgueses.

Nessas condições tudo o que existia na sociedade não poderia ir contra as ações impostas pelos governantes, logo o meio artístico, os preceitos ideológicos, o posicionamento das pessoas e até mesmo a educação, faziam uma ligação de apologia ao militarismo de forma bem explicita. CARNOY (1984) deixa claro que a escola é uma instituição que contribui para a perpetuação de ideais e valores que por vezes legitimam a cultura da classe dominante ao difundir um modo de vida que apenas reforça e coopera para o avultamento da diferença entre os trabalhadores e os detentores do capital.

Mas ao longo do tempo essa situação muda com a queda do regime limitar no governo um novo olhar de teor de liberdade paira toda a sociedade, principalmente a educação que passa ser beneficiada justamente pela presença da inserção de disciplinas que tendem a fazer com que o aluno pense, reflita, além de desenvolver habilidades e competências diversas. Sob tal reflexão é preciso construir a partir da década de 80 , passa configurar uma educação pairava a atender demandas do mercado, direcionada para formação tanto de professores quanto na capacitação de operar as tecnologias diversas, com intuito de garantir as exigências de mundo 
sofisticado em que a melhor maneira de sobreviver por a exploração da força de trabalho humano. RICCI (2003)

E diante de todas essas premissas fazer uma reflexão com a realidade nos dias atuais, analisando as competências que foram preservadas e como a literatura de

\section{METODOLOGIA}

A presente pesquisa parte-se de uma revisão bibliográfica, do tipo sistemática integrativa, que seguiu as seguintes etapas de definição do tema; seleção da pergunta norteadora e escolha da estratégia de busca; descritores e bases de dados mais eficazes no levantamento das publicações; escolha dos critérios de inclusão e exclusão; identificação dos estudos pré-selecionados e selecionados por meio da leitura dos agentes indexadores das publicações, como resumos, palavras-chave e títulos. décadas passadas podem contribuir com o que é passado em sala de aula, metodologias que são aplicadas e como a mesma se correlaciona com outras fontes de artes para que venha empregar um papel de transformação social e cultural.

Assim como a organização dos estudos pré-selecionados e a identificação dos estudos selecionados; categorização dos estudos selecionados, com a elaboração e o uso da matriz de síntese, além da análise das informações; a formação de uma biblioteca individual e a avaliação crítica dos estudos selecionados; análise, interpretação e discussão dos resultados e a apresentação da revisão em formato de artigo, o qual contempla as propostas para estudos futuros.

Quadro 1 - Detalhamento das etapas da Revisão Sistemática Integrativa.

\begin{tabular}{|c|c|c|}
\hline ETAPA & $\begin{array}{c}\text { TÓPICOS DE CADA } \\
\text { ETAPA }\end{array}$ & DETALHAMENTO DE CADA TÓPICO \\
\hline \multirow{4}{*}{$1^{\mathrm{a}}$} & Tema & Evolução do ensino de Literatura no Brasil \\
\hline & Pergunta norteadora & Qual o processo evolutivo passado ao longo das décadas? \\
\hline & Objetivo geral & $\begin{array}{l}\text { Apresentar a realidade vivida durante as últimas décadas } \\
\text { no processo de ensino aprendizagem de Literatura no } \\
\text { Brasil. }\end{array}$ \\
\hline & Estratégias de busca & \\
\hline
\end{tabular}




\begin{tabular}{|c|c|c|c|c|c|}
\hline & & \multicolumn{4}{|c|}{$\begin{array}{l}\text { 1. Cruzamento de descritores por meio do operador } \\
\text { booleano AND; } \\
6 \text {. Uso de descritores estruturados (codificação) no } \\
\text { DECS ou MESH; } \\
7 \text { Uso de metadados (filtros). }\end{array}$} \\
\hline & \multirow{3}{*}{ Bancos de terminologias } & Banco & \multicolumn{3}{|c|}{ Link } \\
\hline & & DeSC & \multicolumn{3}{|c|}{ http://decs.bvs.br/ } \\
\hline & & $\mathrm{MeSH}$ & \multicolumn{3}{|c|}{ https://www.ncbi.nlm.nih.gov/mesh } \\
\hline & \multirow[t]{3}{*}{$\begin{array}{l}\text { Descritores livres e } \\
\text { estruturados }\end{array}$} & Descritor & $\operatorname{DeSC}(\mathrm{Re}$ & egistro) & $\begin{array}{l}\text { MeSH } \\
\text { (Identificador } \\
\text { Único) }\end{array}$ \\
\hline & & Literatura & 5924 & & D005783 \\
\hline & & Educação & 1172 & & D011287 \\
\hline & String de busca & \multicolumn{4}{|c|}{ literatura AND educação AND desafios } \\
\hline & \multirow{4}{*}{ Bibliotecas Virtuais } & \multicolumn{4}{|c|}{ Link } \\
\hline & & BVS & \multicolumn{3}{|c|}{ https://bvsalud.org/ } \\
\hline & & Scielo & \multicolumn{3}{|c|}{ https://search.scielo.org/ } \\
\hline & & PubMed & \multicolumn{3}{|c|}{ https://www.ncbi.nlm.nih.gov/pubmed/ } \\
\hline \multirow{3}{*}{$2^{\mathrm{a}}$} & $\begin{array}{c}\text { Período de coleta dos } \\
\text { dados }\end{array}$ & \multicolumn{4}{|c|}{ Novembro de 2020} \\
\hline & Critérios de inclusão & \multicolumn{4}{|c|}{$\begin{array}{l}\text { 3. Texto (artigo científicos). } \\
\text { 4. Publicação (2016 -2020). }\end{array}$} \\
\hline & Critérios de exclusão & \multicolumn{4}{|c|}{$\begin{array}{l}\text { 2. Artigos que não contemplam a temática } \\
\text { "Literatura". }\end{array}$} \\
\hline $3^{a}$ & \multicolumn{3}{|c|}{$\begin{array}{l}\text { Número de trabalhos selecionados para revisão } \\
\text { sistemática integrativa a partir da leitura dos agentes } \\
\text { indexadores das publicações (tema, descrição, } \\
\text { ementa). }\end{array}$} & & 08 \\
\hline $4^{\mathrm{a}}$ & & & & & \\
\hline
\end{tabular}




\begin{tabular}{|l|l|c|}
\hline & $\begin{array}{l}\text { Categorias obtidas com a análise dos documentos } \\
\text { investigados online gratuitos e de livre acesso }\end{array}$ & 2 \\
\hline
\end{tabular}

Fonte: elaborada pelos autores.

\section{RESULTADOS}

Quadro 2 - Corresponde ao total de documentos disponíveis nas Plataforma BVS, Scielo, PubMed obtidos por string de busca.

\begin{tabular}{|c|c|c|c|c|}
\hline \multirow{2}{*}{ String de busca } & $\begin{array}{c}\text { Bases de } \\
\text { dados } \\
\text { Plataforma }\end{array}$ & $\begin{array}{c}\text { Total de } \\
\text { publicações } \\
\text { sem o filtro }\end{array}$ & $\begin{array}{c}\text { Publicações } \\
\text { disponíveis após } \\
\text { aplicar os filtros }\end{array}$ & $\begin{array}{c}\text { Publicações } \\
\text { aproveitadas na } \\
\text { Revisão Sistemática } \\
\text { Integrativa }\end{array}$ \\
\hline \multirow{2}{*}{$\begin{array}{c}\text { Preconceito AND } \\
\text { Gênero AND } \\
\text { Igualdade }\end{array}$} & BVS & 143 & 35 & 5 \\
\cline { 2 - 5 } & Pcielo & 4 & 2 & 2 \\
\cline { 2 - 5 } & PubMed & 4 & 1 & 12 \\
\hline
\end{tabular}

Fonte: elaborada pelos autores.

Dentre a analise realizada nos sites optados para investigação bibliográfica, constatou-se em trono aproximado de 151 publicações científicas nos bancos de dados, no qual entre elas apresentam um quantitativo de 38 sendo todos artigos, no qual eram disponíveis após o uso dos filtros, dentre eles 08 downloads, que obedeceram às características de critérios de inclusão, sendo submetidos às etapas da revisão integrativa.

Quadro 3 - Descrição dos documentos (artigos) de acordo com os critérios de inclusão.

\begin{tabular}{|c|c|c|c|l|}
\hline Artigo & Autor(a) & \multicolumn{1}{|c|}{ Tema } & $\begin{array}{c}\text { Ano da } \\
\text { publicação }\end{array}$ & \multicolumn{1}{c|}{ Conclusão } \\
\hline \multirow{4}{*}{01} & $\begin{array}{l}\text { Brito Delabona Boutin } \\
\text { Carla Roseane Sales } \\
\text { Camargo }\end{array}$ & $\begin{array}{l}\text { A educação na } \\
\text { ditadura militar } \\
\text { e as estratégias } \\
\text { reformistas em } \\
\text { favor do capital }\end{array}$ & 2015 & $\begin{array}{l}\text { Mostrou uma reflexão crítica } \\
\text { mediante as estratégicas } \\
\text { reformistas para educação, em } \\
\text { favor da hegemonia e até } \\
\text { mesmo legitimação do sistema } \\
\text { capitalista, deixando heranças } \\
\text { ideológicas contribuindo para o }\end{array}$ \\
\hline
\end{tabular}




\begin{tabular}{|c|c|c|c|c|}
\hline & & & & $\begin{array}{l}\text { ensino direcionado para que os } \\
\text { discentes não se reconheçam } \\
\text { enquanto seres históricos, } \\
\text { capazes de romper estruturas } \\
\text { alienantes presentes ao meio } \\
\text { social. }\end{array}$ \\
\hline 02 & Olavo de Carvalho & $\begin{array}{c}\text { Fórum da } \\
\text { Liberdade } 2019\end{array}$ & 2019 & $\begin{array}{l}\text { Dessa maneira, apresenta a } \\
\text { literatura como uma } \\
\text { compreensão social, diante das } \\
\text { experiências acumulativas, } \\
\text { narradas para com a } \\
\text { individualidade do ser e suas } \\
\text { respectivas experiências. } \\
\text { Representando assim dessa } \\
\text { maneira aspectos humanos e } \\
\text { aquisições diversas, em fatos, } \\
\text { crenças e desejos diversos. }\end{array}$ \\
\hline 03 & $\begin{array}{c}\text { Miriam Coutinho de } \\
\text { Faria Alves }\end{array}$ & $\begin{array}{c}\text { A memória } \\
\text { afetiva e a } \\
\text { infância digna } \\
\text { na literatura de } \\
\text { Clarice } \\
\text { Lispector. } \\
2016\end{array}$ & 2016 & $\begin{array}{c}\text { O objetivo refletir a partir da } \\
\text { perspectiva jusliterária, sobre a } \\
\text { construção da memória afetiva } \\
\text { enquanto categoria do } \\
\text { imaginário dos direitos da } \\
\text { criança. Nesse sentido, } \\
\text { examina as interligações entre } \\
\text { as memórias da infância e a } \\
\text { personalidade adulta da } \\
\text { personagem Virgínia na obra } \\
\text { O lustre de Clarice Lispector } \\
\text { para assim tematizar a função } \\
\text { da memória afetiva e o direito } \\
\text { à infância digna. Diante disso, } \\
\text { analisa-se a função das } \\
\text { recordações afetivas no } \\
\text { processo de formação da } \\
\text { identidade o que contribui para } \\
\text { investigar como se estruturam }\end{array}$ \\
\hline
\end{tabular}




\begin{tabular}{|c|c|c|c|c|}
\hline & & & & $\begin{array}{c}\text { as impressões que conformam } \\
\text { a construção jurídica dos } \\
\text { direitos da criança. }\end{array}$ \\
\hline 04 & Hilda Bentes & $\begin{array}{l}\text { O ponto de } \\
\text { convergência } \\
\text { entre o teatro e a } \\
\text { filosofia: o } \\
\text { verbo } \\
\text { "théorein". } \\
2016\end{array}$ & 2016 & $\begin{array}{c}\text { O objetivo examinar de modo } \\
\text { filosófico a relação intrínseca } \\
\text { entre o teatro e a filosofia a } \\
\text { partir do estudo do verbo } \\
\text { théorein, revelador de } \\
\text { instigantes elementos } \\
\text { constitutivos da arte dramática } \\
\text { e da maestria especulativa. } \\
\text { Cuida-se de um aprendizado } \\
\text { do olhar que, no teatro e na } \\
\text { filosofia, irá encontrar as } \\
\text { condições propícias para o seu } \\
\text { pleno exercício nas } \\
\text { manifestações artísticas e } \\
\text { filosóficas do século V a.C. } \\
\text { em Atenas. }\end{array}$ \\
\hline 05 & Hilda Bentes & $\begin{array}{c}\text { A “via crucis” } \\
\text { do corpo da } \\
\text { mulher: trajetos } \\
\text { de violência na } \\
\text { literatura } \\
\text { brasileira sob a } \\
\text { ótica dos } \\
\text { direitos } \\
\text { humanos das } \\
\text { mulheres. } \\
2016\end{array}$ & 2016 & $\begin{array}{c}\text { Propõe-se analisar os trajetos } \\
\text { de violência contra a mulher } \\
\text { na literatura brasileira sob a } \\
\text { perspectiva dos direitos } \\
\text { humanos da mulher. Busca-se } \\
\text { uma articulação entre a } \\
\text { literatura, a filosofia e o } \\
\text { direito. Numa abordagem } \\
\text { interdisciplinar, o artigo } \\
\text { examina a constituição de um } \\
\text { sujeito do direito, através do } \\
\text { conceito de capacidade, } \\
\text { elaborado por Paul Ricoeur, } \\
\text { aplicável à condição ainda } \\
\text { precária da mulher. }\end{array}$ \\
\hline 06 & $\begin{array}{c}\text { Marcílio Toscano } \\
\text { França Junior }\end{array}$ & $\begin{array}{l}\text { Antimanual de } \\
\text { Direito e Arte }\end{array}$ & 2016 & $\begin{array}{l}\text { Antimanual de Direito \& Arte } \\
\text { é uma coletânea original de }\end{array}$ \\
\hline
\end{tabular}




\begin{tabular}{|c|c|c|c|c|}
\hline & & 2016 & & $\begin{array}{c}\text { ensaios jurídicos muito } \\
\text { criativos, pouco canônicos e } \\
\text { nada dogmáticos (daí o termo } \\
\text { "Antimanual"), no qual cada } \\
\text { autor tratou de estabelecer um } \\
\text { diálogo peculiar entre o direito } \\
\text { e uma manifestação artística. } \\
\text { Assim, há capítulos sobre } \\
\text { Direito \& Ópera, Direito \& } \\
\text { Arquitetura, Direito \& Cultura } \\
\text { Pop, Direito \& Cinema, } \\
\text { Direito \& Teatro, Direito \& } \\
\text { Artes Plásticas etc., de autoria } \\
\text { de juristas, professores e } \\
\text { literatos do Brasil e do exterior } \\
\text { interessados em expandir com } \\
\text { novos olhares o estudo da } \\
\text { juridicidade. }\end{array}$ \\
\hline 07 & Carlos H. A. Corrêa & $\begin{array}{c}\text { Notas de estudo: } \\
\text { a história } \\
\text { cultural e as } \\
\text { possibilidades } \\
\text { de pesquisar } \\
\text { leitura. } \\
2017\end{array}$ & 2017 & $\begin{array}{c}\text { Traçar preceitos que façam } \\
\text { com que interacione ideias } \\
\text { diversas de configuração } \\
\text { branda sobre questões } \\
\text { específicas da cultura e } \\
\text { história brasileira e a } \\
\text { contribuição tida na mesma } \\
\text { para os conhecimentos ativos } \\
\text { dos alunos. }\end{array}$ \\
\hline 08 & Aline Cezar Schwab & $\begin{array}{l}\text { Listas de obras } \\
\text { literárias no } \\
\text { vestibular: } \\
\text { espaço de } \\
\text { (r)eexistência da } \\
\text { literatura no } \\
\text { contexto escolar } \\
2020\end{array}$ & 2020 & $\begin{array}{c}\text { O presente trabalho foi } \\
\text { desenvolvido a partir da } \\
\text { preocupação em refletir sobre } \\
\text { a influência que os exames de } \\
\text { seleção para acesso ao ensino } \\
\text { superior exercem sobre os } \\
\text { modos de conduzir o ensino de } \\
\text { literatura no ambiente escolar. } \\
\text { É frequente nos vestibulares }\end{array}$ \\
\hline
\end{tabular}




\begin{tabular}{|l|l|c|c|}
\hline & & $\begin{array}{c}\text { que a disciplina seja abordada } \\
\text { em questões geradas a partir } \\
\text { de uma lista de obras literárias } \\
\text { cuja leitura é indicada como } \\
\text { obrigatória para a realização } \\
\text { das provas. }\end{array}$ \\
& & \\
& & \\
& &
\end{tabular}

Fonte: Plataformas: BVS, Scielo e PubMed, 2020.

Tabela 1. Frequência das palavras presentes nos textos publicados pelos artigos nas Plataformas: BVS, Scielo e PubMed.

\begin{tabular}{l|c|l}
\hline \multicolumn{1}{c|}{ PALAVRAS } & FREQUÊNCIA & \multicolumn{1}{c}{ CATEGORIAS } \\
\hline Literatura/Perfil social & 9 & $\begin{array}{l}\text { A Literatura como ferramenta de formação do } \\
\text { perfil social }\end{array}$ \\
\hline Literatura/Ditadura & 7 & A Literatura nos dias de ditadura \\
\hline Literatura/após o regime & 6 & $\begin{array}{l}\text { A Literatura após rompimento do Regime } \\
\text { Militar }\end{array}$ \\
\hline Literatura/contemporaneidade & 7 & \multicolumn{1}{c}{$\begin{array}{c}\text { A importância da Literatura para } \\
\text { contemporaneidade }\end{array}$} \\
\hline Literatura/Educação & 10 & Literatura contemporânea e a educação \\
\hline
\end{tabular}

Fonte: Autora

\section{DISCUSSÃO}

\section{A LITERATURA COMO FERRAMENTA DE FORMAÇÃO DO PERFIL SOCIAL}

A literatura é algo que ultrapassam décadas e perpetuam gerações, é por meio da mesma que nações conservam conhecimentos milenares de seu povo e ainda pairam uma configuração onipotente do campo artístico, como a própria arte, representada pela a música, dança o canto e até mesmo as artes plásticas. Desde o período neolítico poderia ver que os homens primitivos se reuniam para criarem palavras para nomeações de objetos, ações e práticas e ensinar aos demais membros de seu clã, assim iniciavam narrar fatos tidos no cotidiano e a partir daí favorecendo ao surgimento dos mitos e crenças.

De acordo com CARVALHO (2019), a literatura é vista como uma compreensão da sociedade, ciências ou qualquer coisa particular, mas trata-se de uma experiência acumulada e narrada da vida, na individualidade não se pode viver todas as experiências "noventa e noves por 
cento das experiências são acumuladas dos outros". A mesma é vista como um núcleo de experiência humana, sendo representados como aspectos humanos de experiências diversas, resultado de aquisições diárias, fatos, crenças, desejos ou meras justificativas.

Dessa forma, vale ressaltar que tudo o vivencia-se atualmente será resultado em síntese de possíveis fatores para com o desencadeamento de preceitos literários, seja posicionamento sobre temas diversos, compreensão social, constituição de teses ou até as obras produzidas na contemporaneidade, como exemplo pode ser citados os livros, as tele dramaturgias, ou até mesmo os gibis, que já caracterizam bastante a realidade da vida de crianças e jovens desde a década de 80 , em exemplo temos os autores Maurício de Souza e Ziraldo.

Diante desses fatos percebe-se também que a literatura é algo elementar justamente para a formação do caráter humano e compreensão da conduta histórica da sociedade. Já que a mesma tende a apresentar em suas obras fragmentos que compõem a realidade vivida, ao ler uma obra como o Guarani, pode perceber a mentalidade das pessoas naquela época, ao analisar o livro Lucíola, conhece sobre a conduta empregada em décadas passadas, os preconceitos, temas polêmicos e assuntos que inquietam as pessoas.

A mesma é uma das condutas que abrangem um pensamento crítico por meio da transdisciplinaridade, apresentando uma forma de desconstrução mediante dos saberes que são impostos, assim como também são instruídos, pode analisar que existem brasileiros que referenciam as palavras de teóricos, dentre esses destacamse o próprio Jorge Amado, assim como Mario Andrade, sendo a base para ruptura com modelo de pedagogia convencional.

PEPE (2016), aponta que alguns personagens desses autores emergem no pensamento, mediante as relações entre a tradição exercida de um povo e sua literatura, alguns com famas e cronópios, das histórias e o próprio reconhecimento, como é no caso de Dona Flor, Vadinho e Teodoro, de Dona Flor e os seus dois maridos, de Jorge Amado, compondo tetos surrealistas criados na produção de um clima, de um ambiente, de uma atmosfera, no qual a literatura aproxima a cada reflexão.

$\mathrm{O}$ autor faz referência a obra de Jorge Amado, afim de fazer uma relação com a importância que as obras tenham para a formação do caráter social da população, ideias que ao longo do tempo passam a madurecer e até mesmo temas que façam com que o aluno reflita e venham a debater sobre os mesmos, a literatura em si, surge 
para inquietar os cidadãos, trazendo temáticas que dividam no qual existam pessoas que os defendam e aqueles também que os rejeitam, e assim permeiem o debate e obtenham uma síntese do que é retratado refletindo para a sociedade.

A fixação e a associação de temas contemporâneos levam as pessoas sintetizarem conteúdos de forma passiva e assim quebrar alguns preconceitos e fazer com que se sensibilizem com conteúdo diversos, afinal quem nunca refletiu sobre o amor desencadeado de uma mera prostituta e um rapaz de família como ressaltado na obra Lucíola de José Alencar, ou até mesmo a relação existente entre índios nativos e os homens brancos, retratado em Iracema.

A literatura também é libertadora, com a mesma os indivíduos passam a assumir comportamentos semelhantes aos personagens heroicos dos mesmos, o perfil desbravador dos protagonistas, um olhar mais humano das mocinhas, e repudiando tudo que se enquadra como comportamento similar dos vilões e passando comparar sua vida com a da obra.

\section{A LITERATURA NOS DIAS DE DITADURA}

O Golpe Militar de 1964, é marcado por um cenário de medo, angústia e opressão dos cidadãos brasileiros, todas práticas e ações eram mediadas e limitadas através de entidades governamentais, com isso muitos cidadãos eram privados de atividades atualmente consideradas básicas, e no campo educacional, o professor tinha que seguir uma linha no qual formaria um aluno vazio, sem perspectiva de evolução e apenas mais uma "marionete do sistema".

A maior violência que ainda pairam marcas na contemporaneidade é a herança ideológica, como afirma BOUTIN e CAMARGO (2015), deixou tatuado na sociedade preceitos que configuram a subordinação, a falta de senso crítico e até mesmo a passividade. Assim a sociedade acaba muitas vezes se omitindo a discussões que atingem principalmente ao proletariado, fazendo com que os cidadãos aceitem o que são impostos e não lutem através de melhoras.

Um grande disseminador dessa ideia imposta a sociedade foi justamente através da educação, o governo tinha como ideal principal o modelo capitalista, que por sua vez queriam que os discentes saíssem das salas de aula com conhecimentos técnicos e centrados unicamente ao campo de trabalho, com uma identidade corrompida, seguida apenas para servir seu patrão e buscar com todas as forças evoluir de cargo através da confiança lhe dada e o respeito tido para com seus superiores.

Dessa maneira, tudo que era imposto era aceito, todas as decisões não levavam em conta o que os funcionários pensavam, eles eram submetidos a realizarem tarefas 
exaustivas diárias e aquele que não se sentisse apto ao mesmo era descartado como um simples objeto. Se os dias atuais é notado que muitos trabalhadores não são valorizados, durante a ditadura essa situação era ainda pior.

Diante disso, apenas disciplinas base eram empregadas, ligadas ao conhecimento linguístico, ao aspecto matemático e as atividades técnicas, áreas como literatura, história, filosofia, sociologia, arte, eram totalmente vetadas, uma vez que o aluno tinha que ter domínio no campo industrial e não conhecimento de teorias, teses e até teoremas que os faziam pensar.

[...] a partir do pressuposto da neutralidade científica e inspirada nos princípios da racionalidade e eficiência e produtividade, a pedagogia técnica advoga a reordenação do processo educativo de maneira a torna-lo objetivo e operacional. De modo semelhante ao que ocorreu no trabalho fabril, pretende-se a objetivação do trabalho pedagógico (SAVIANI, 2009, p. 11).

O preceito trazido pela pedagogia técnica era justamente a busca do reordenamento educacional com vistas a produtividade, com as proposições para o ensino com uma sistemática pautada por uma ideia acometida em situações limitadas, no qual os alunos eram ensinados a serem subordinados a partir da sala de aula quando os professores eram considerados os detentores únicos e exclusivos do conhecimento, e os alunos meros ouvintes.

A literatura nessa época era apresentada através de obras conhecidas como romances-reportagens, mediante as ideias de Ênio Silveira, no qual apresentava histórias reais, com contornos ficcionais, apesar de bem visto pela crítica e ter permitido o movimento no mercado editorial, os jornalistas-escritores não foram bem vistos pela censura, apesar dos mesmos quererem apresentar a realidade ao povo, se deparavam com os grupos de extermínio incentivados pelo governo.

Nessas condições pode-se constatar que a literatura era algo que praticamente era vetada a sociedade, não tinha o incentivo que hoje é dado nas escolas, nem muito menos haviam programas de caráter público no qual oferta um incentivo aos alunos para interação com os mesmos, apresentando como algo inútil, e dessa forma afastando seus admiradores de uma premissa tão rica socialmente e transformadora.

Era justamente o fator de transformação que assustava os governantes, para os mesmos o indivíduo que nascesse em situações proletarizadas, eles não poderiam ter acesso a condições que permitissem sair da mesma, era uma 
teoria semelhante a empregada no antigo Egito, um indivíduo que nascesse escravo tinha que morrer escravo, da mesma forma que o indivíduo que nascesse burguês não haveria hipótese alguma de migrar para uma classe inferior, assim todas as formas de fazer com que os indivíduos encontrassem independência dessa opressão social arcaica era vetada, assim como educação de qualidade, visões aprofundadas sobre questões sociais e que iriam contra o capitalismo e governo.

\section{A LITERATURA APÓS O ROMPIMENTO DO REGIME MILITAR}

Com o fim da ditadura militar, em muitos cenários teve a evolução de ideias no qual trazia como premissa ideologias totalmente contrarias do que eram empregadas, em destaque na própria Educação. Inicialmente a preocupação estava centrada a propostas de efetivação do direito dos cidadãos em garantia com o estado, valorizando a abertura de mais escolas em regiões interioranas e incentivo não único e exclusivo para o mercado de trabalho, mas também para formação social e cultural do aluno.

Dessa maneiras áreas que eram pouco abordadas em décadas anteriores a queda do regime militar, passaram trazer uma nova realidade a sociedade, fazendo com que o alunos saíssem da escola não como apenas pessoas aptas ao mercado de trabalho, mas um seres conscientes da realidade existente a sua volta, passando ser critério essencial para o desenvolvimento de ideias diversas, apontando que um aluno satisfatório era aquele que teria o conhecimento vasto em áreas diversas, principalmente aquelas que lhe fazia refletir sobre a importância de sua existência e preceitos que poderiam ser desencadeados através da mesma.

Os próprios PCNs (2006) apontam que o Ensino Médio, é pairado ao estudo da Literatura, em que os alunos passam ter contato aos múltiplos textos que configuram a história da Língua Portuguesa e até mesmo a constituição dos sotaques brasileiros, no qual a Literatura, tende a informar desde vivências, experiências e possibilite a constituição no aluno de um pensamento crítico e reflexivo, auxiliando na formação profissional, pessoal e até mesmo social.

As obras fazem com que o aluno se torne mais culto, consciente a realidade existente e realize reflexões diversas, por meio das obras vem fazer com que traga a temática para os dias atuais e observar o posicionamento apresentado pelos personagens, e sintetizar, qual a melhor atitude a tomar em frente a realidade, conhecer também preceitos que compõem demais áreas como Filosofia e Sociologia, que parte de um perfil semelhante a mesma, 
desacreditada por muitas pessoas, mas que abrange o desencadeamento de muitas habilidades e competências.

Em 2010, o Senado aprova um projeto de lei do senador Sergio de Souza no qual soma com os preceitos atribuídos a LDB-96, no qual inclui no currículo do Ensino Fundamental a disciplina de Cidadania, Moral e Ética, e, no ensino médio, a disciplina Ética Social e Política, prevendo inserção das disciplinas de Filosofia e Sociologia no ensino médio, no qual o pensamento crítico agia de conjunto com sua ideologia, em sua justificativa ele afirma:

Estou convencido de que, dessa forma, estaremos oferecendo a nossa sociedade instrumentos para o fortalecimento da formação de um cidadão brasileiro melhor, por um lado, pela formação, ensinando conceitos que se fundamentam na obediência a normas, tabus, costumes ou mandamentos culturais, hierárquicos ou religiosos; por outro lado, pela formação ética, ensinando conceitos que se fundamentam no exame dos hábitos de viver e do modo adequado da conduta em comunidade, solidificando a formação do caráter; e finalmente para sedimentar o exercício de uma visão crítica dos fatos sociais e políticos que figuram, conjunturalmente, na pauta prioritária da opinião pública, oferecendo aos jovens os primeiros contatos com as noções de democracia, sem caráter ideológico, ensinando-o a construir seu pensamento político por sua própria consciência. (PLS n. 2/2012)

É notado que as disciplinas que eram vetadas pelo regime militar justamente caracterizavam como aquelas que faziam com que o aluno se soma conhecimentos diversos de premissa cultural e social, no qual estimulados permite com que o mesmo possa se contrapor situação que são impostas e as reflexões mediadas no seu cotidiano.

Configuram um novo olhar, amplo, generalizado e transformador, que não tem como objetivo principal apenas o ingresso em uma indústria, mas fazer com que seja ouvido e tenha base conhecimentos variados de grandes autores como Machado de Assis, José Saramago, William Shakespeare, Fiódor Dostoiévski, Jorge Luís Borges, Franz Kafka, Gabriel García Márquez, dentre outros.

Apesar de todas as vantagens que pode ser percebida pela introdução da Literatura em sala de aula, assim como demais áreas, e benefícios desencadeados pela sociedade, é verídico que os alunos podem sim trazer para sua realidade múltiplos fatores positivos, logo vale ressaltar que não só depende do interesse do aluno nas aulas literárias, mas também a metodologia que é empregada aos mesmos e abordagem que pairam nessas aulas. 


\section{A IMPORTÂNCIA DA LITERATURA PARA CONTEMPORANEIDADE}

É notório que a literatura é de essencial importância para com o ensino de Língua Portuguesa, já quanto mais os alunos realizam boas leituras, assimilam mais habilidades e competências para que formate um mecanismo de funcionamento da língua tanto de caráter oral quanto escrita, a metodologia que é imposta pelos livros didáticos atualmente é justamente a associação entre gramática e literatura, em que através do contato de texto e até mesmo as obras, passa aprender tanto preceitos de coesão, coerência e orientações gramaticais, assim como também conhecer questões sociais e culturais.

Só que para atender tal premissa, os educadores devem buscar concepções metodológicas, em que constituem e formatem abordagens em que os alunos possam alcançar tais resultados. Segundo BRAGA e SILVESTRE (2009), o aluno tende a construir sentido por meio de conhecimentos e expectativas diversas, a leitura é feita através a explicação de um assunto, e tenha a ampliação de um conhecimento, ou por qualquer motivo, "o professor deve ser o responsável da transformação do que precisa ser tido favorecendo em algo significativo e prazeroso".

Assim, antes da aplicação de obras em uma sala, o professor deve realizar um diagnóstico da realidade vivida pelos alunos e trazer obras contemporâneas ou tradicionais que façam com que tragam um significado e faça com que o mesmo reflita sobre sua realidade, fazendo com que contextualize com a mesma e traga uma nova roupagem para a sua vida.

As atividades executadas por um professor centralizam-se na prática de classe, direcionado as suas aulas de literatura, a base da mesma parte das ideias estabelecidas do Ministério da Educação e Cultura (MEC), os Parâmetros Curriculares Nacionais (PCN) e da própria Base Nacional Comum Curricular (BNCC), no qual a união dos três permite com que renda condições para que os estudantes tenham contato com o leque de conhecimento a sociedade favorecendo para formação como cidadão.

O valor da literatura passou ser tão abrangente nos últimos anos que a procura por a mesma afim de tomar como base de especialização ou até mesmo cursos de complementares tem aumentado significativamente, não só por profissionais de ensino como também por demais cidadãos, a mesma vem justamente quebrando paradigmas e fazendo com que os alunos cresçam, maximize suas concepções teóricas e ainda resgatem preceitos que foram rompidos durante o período da ditadura. 
MACHADO (2002) já deixa claro em suas obras que a leitura é tida como uma arma de libertação da alienação e opressão estabelecida pela sociedade, por meio de obras diversas o indivíduo passa conhecer a herança deixada por autores consagrados e identificar preceitos históricos que compõem o Brasil. Também age como uma tarefa multidisciplinar, já que é conhecido preceitos culturais, geográficos, antropológicos, e que leva o aluno alcançar objetivos que seriam mais complicados em conseguir quando estudado separadamente.

$\mathrm{O}$ direito e a resistência como apontado pela autora é o que media a construção de um conhecimento pairado nas reflexões diversas das obras, reconfigurando o sentido do significado das palavras e não só limitando no desencadeamento de ideias no âmbito escolar, mas façam refletir também na sociedade, podendo dessa forma já atingir um objetivo que era alvo em décadas passadas e que ainda continua sendo na escola em questão que é justamente preparar o aluno para as atividades trabalhistas e reconfiguração do seu perfil social. Segundo MACHADO (2002, p. 20):

Lendo uma história, de repente descobrimos nela umas pessoas que, de alguma forma, são tão idênticas a nós mesmos, que nos parecem uma espécie de espelho. (...). Alguns livros acabam nos ajudando a entender melhor o sentido de nossas próprias experiências.

O livro também passa questionar, desafiando recursos da consciência e o próprio intelecto, ampliando um novo horizonte e também fazendo questionamentos próprios e enriquecendoos, apresentando comportamentos passados, a evolução da linguagem, jargões, gírias e até mesmos costumes. Nessas condições vale ressaltar que o educador passa a defender a Língua Portuguesa valorizando a importância de tais práticas, enfatizando mecanismos que façam com que formate no aluno um comportamento de um leitor capaz desde processar, criticar, contradizer e até mesmo avaliar.

\section{LITERATURA CONTEMPORÂNEA E A EDUCAÇÃO}

A passagem do século $\mathrm{XX}$ para o século XXI apresenta uma série de mudanças no comportamento das pessoas, que permitem com que reformulem preceitos direcionados a cultura, sociedade, reflexões, posicionamentos e até mesmo no aparato inovador. Apresentando uma nova realidade para as civilizações mundiais, no qual a tecnologia e a informação movem as pessoas, chegando ao ponto de dominar pensamentos e opções humanas, se tornando as regras ditadoras.

Com isso a sociedade dos anos 2000, como apresenta SEVCENKO (2004) 
“possuem novas buscas, possibilidades, outros desejos e também anseios que pairam de uma sociedade consumista", porém globalizada, com isso interfere também até mesmo na educação, em caráter negativo pode-se citar a desvalorização da velha metodologia empregada nas décadas que antecedem a mesma, por outro lado vem fazer com que os alunos tenham mais facilidade em encontrar informações, interagir com pessoas em diferentes partes do mundo e até mesmo concretizando metodologias em que façam com que a aula seja mais atrativa e dinâmica.

Os seres humanos vivem uma rotina cada vez mais agitado no qual apresenta um desejo de viver de forma mais rápida, e ao mesmo tempo apresentando uma realidade contínua e ininterrupto. O conceito de literatura, assim passa apresentar uma variância sincrônica epistemológica, no qual acompanha a passagem de um século a outro, de preceito analógico ao informático.

Além da flexibilidade com o conceito de literatura, o diálogo com outras interfaces constitui ponto inicial para $\mathrm{o}$ elenco de obras no fim de século $\mathrm{XX}$. SANT' ANNA aponta que a poesia literária havia de certa forma destruído o poema e o verso, fazendo com que chegasse a pontos nunca imaginados, foi no momento que a poesia começou a ser servida em forma musical com muita eficiência política e estética, usufruindo de ferramentas hoje como os best seller, a música e até mesmo as telenovelas.

Com as telenovelas, autores conseguem apresentar e associar preceitos literários no qual, preenche lacunas contemporâneas, mesmo fugindo do padrão de cultura impressa. Mesmo podendo apresentar como o rompimento da própria leitura extraída de livros diversos, também pode ser visto que pode ser um incentivador para com a literatura clássica, já que essa é uma forma de oferecer ao telespectador reflexões através de adaptações diversas, possibilitando também que os demais sejam instigados a lerem a obra na integra, analisando pontos de comparação entre a dramaturgia e o livro, e assim sucessivamente.

Pode perceber principalmente no início dos anos 2000, muitas obras foram adaptadas e produzidas para as telas do cinema, como a trilogia dos livros de J.K. Rowling, produzindo oito livros e ganhando uma legião de admiradores, o livro "As crônicas de Nárnia", que apesar de já ter sido adaptada para rádio, TV e teatro desde a época em que foi lançado entre 1949 e 1954, ganhou grande prestigio e produziu três filmes, pode-se citar vários outros filmes como: A barraca do beijo de Beth Reekles; Caixa de pássaros de Josh Malerman; After de Anna Todd, dentre outros. 
E não só de origem internacional, como também as obras nacionais já fazia bastante sucesso até mesmo na década passada quando eram adaptadas para o rádio e com a chegada da TV isso que lhe deu oportunidade para um crescimento nunca imaginado, dentre as obras que se transformaram em telenovelas há Gabriela, Cravo e Canela de Jorge Amado, que já teve duas adaptações, A Escrava Isaura de Bernardo Guimarães, Sinhá Moça de Maria Dezonne, dentre outras que serviram de inspirações e consagrando ainda mais o nome de autores como José de Alencar, Jorge Amado, Roberto Drummond, Nelson Mota, dentre outros.

Sem falar de autores contemporâneos que escrevem histórias atuais chamando atenção de diretores e as adaptando para o meio televisivo como A cinco passos de você, de Rachael

\section{CONCLUSÃO}

O presente trabalho traz consigo a composição vigente das premissas literárias no ensino de Educação Básica, principalmente em rede pública ao longo do tempo, em que expõem preceitos que fazem com que o aluno tenha sua evolução ativa ao meio social da mesma maneira que também permita com que o professor trace estratégias diversas que alcancem novas vertentes que não se limite apenas
Lippincott; Com amor, Simon de Becky Albertalli; Jardim Secret de Frances Hodgon Burnett; Uma dobra no tempo de Madeleine L'Engle, dentre outros, que fazem com que leve o público infantojuvenil refletirem com os dilemas que vivem em sua vida como dramas amorosos, preconceito, a perca precoce dos pais, o processo de amadurecimento, dentre outros preceitos.

A Literatura é algo vivo e essencial para vida de todo ser humano, é através da mesma que aluno passa ter um olhar mais panorâmico da vida, que acaba associado questões sociais e culturais fazendo dialogar entre uma realidade contemporânea e passada, possibilitando o desenvolvimento de competências variadas para formação do perfil contemporâneo da sociedade.

composições vazias, inseguras e que não levem a reflexão.

De modo geral, mais do que evoluir o pensamento do aluno de acordo com seu posicionamento científico, também cabe a ideias diversas que façam com que conciliem contextos sociais, culturais e pragmáticos de uma realidade que perpetua as pessoas e fazem com tenha uma aproximação de ideias contemporâneas e de libertação de pensamento, já que apesar de muitos anos terem se passado, é notório que 
há muitos posicionamentos decorrentes nas instituições de ensino que fazem com que favoreça o comportamento empregado na sociedade durante os anos que imperaram o regime militar.

Como forma de libertação, existe a Literatura, que faz com que contextualize com o ensino moderno e faça com que os alunos possam refletir sobre temas diversos e tragam para suas vidas reflexões dos mesmos, sem perder de fato sua própria identidade e favorecer sua visão própria sobre alguns direcionamentos. Diferente do que muitos apontam, na escola não é apresentado fórmulas prontas, ao contrário é através dos mesmos que os alunos devem buscar, lugar e correr atrás para que tenha uma visão generalizada de vida, e defenda o que acredita.

\section{REFERÊNCIAS}

ALVES, Miriam Coutinho de Faria. A memória afetiva e a infância digna na literatura de Clarice Lispector. Anamorphosis-Revista Internacional de Direito e Literatura, v. 2, n.1, p. 169-181, 2016.

BENTES, Hilda. A "via crucis" do corpo da mulher: trajetos de violência na literatura brasileira sob a ótica dos direitos humanos das mulheres. Anamorphosis-Revista Internacional de Direito e Literatura, v. 2, n.1, p. 147-167, 2016.

BENTES, Hilda. O ponto de convergência entre o teatro e a filosofia: o verbo
Tudo isso oferecerá conquistas que possibilitará com que aja uma evolução ativa na sociedade, não apenas restringindo a ideias vãs, mas que a mesma possa ter uma visão mais diversificada, não fique na restrição de seguir o que é proposto, mas tenha vontade própria, por mais que não concorde faça com que tenha a síntese de teses contra argumentativas para que só assim, problemas e rupturas sociais passem não mais existir, como é no caso de preconceito, intolerância ou até mesmo educar as pessoas a saberem se posicionar, não é agredindo ninguém verbalmente que chegasse a lugar algum, mas tendo empatia, e todos esses pontos são abordados a décadas passadas que trazem nos seus livros fragmentos dessa realidade, deixando os alunos mais seguros e também confiantes.

"théorein". Synesis (on line), v. 8, p. 80100, 2016.

BOUTIN, Aldimara Catarina Brito Delabora, CAMARGO, Carla Roseane Sales. A educação na ditadura e as estratégias reformistas em favor do capital - Formação de Professores, complexidade e trabalho docente SIPD/Catedra Unesco, out. 2015

CARNOY, M. Educação economia e Estado: base e superestrutura e relações de mediação. 3 ed. São Paulo: Cortez, 1984.

CARVALHO, Olavo de. Olavo no Fórum da Liberdade 2019. Disponível em: $<$ https://www.youtube.com/watch? $\mathrm{v}=\mathrm{xCfF}$ mQiVEds\&t=1050s $>$. Acesso em: $23 \mathrm{Nov}$. 2019 
CUNHA, L.A.; FERNANDES, V. Um acordo insólito: ensino religioso sem ônus para os poderes públicos na primeira LDB. Educação \& Pesquisa, São Paulo, v. 38, n. 4, p. 849-864, out./dez. 2012.

MACHADO, Ana Maria. Como e por que ler os clássicos universais desde cedo. Rio de Janeiro: Objetiva, 2002.

Parâmetros Curriculares Nacionais: o currículo da Língua Portuguesa e da Literatura no ensino médio. $14^{\circ}$ ed. Brasília, Distrito Federal, Editora FTD, 2006.
PEPE, Albano Marcos Bastos. Direito e Literatura: uma intersecção possível? Interlocuções com o pensamento waratiano. Anamorphosis - Revista Internacional de Direito e Literatura. v. 2, n. 1, p. 5-15, jul.-dez. 2016. http://dx.doi.org/10.21119/anamps.21.5-15

SAVIANI, D. Escola e Democracia. Campinas: Autores Associados, 2009.

SEVCENKO, Nicolau. A corrida para o século XXI: no loop da montanha-russa. $6^{a}$ reimpressão. São Paulo: Companhia das Letras, 2004. Coleção Virando Séculos, v. 7. 